\title{
Effect of Low Temperatures on Metals
}

$S^{1}$ INCE the year 1905, when Sir Robert Hadfield and the late Sir James Dewar described the effect of liquid air temperatures on the strength of iron and its alloys, there has been not only a very considerable advance in low temperature technique, but also many types of new metallurgical materials have been successfully developed. Many alloys which are to-day in extensive use as parts of machines and structures were quite unknown at the time of that research.

The importance of low temperature research was recognised many years earlier than 1905 in view of the severe winter conditions experienced in northern Continental lands. In research work of the future, still greater attention is likely to be paid to the study of low temperature phenomena in relation to the physical and engineering sciences.

Recently Prof. W. J. de Haas and Sir Robert Hadfield* have described to the Royal Society the results of a further important research on the mechanical properties of these materials at the boiling point of liquified hydrogen $\left(-252 \cdot 8^{\circ} \mathrm{C}\right.$.). This work has extended the range of study of the properties of metals a further $60^{\circ} \mathrm{C}$. and thus the strength of these metals is now known at $20 \cdot 3^{\circ} \mathrm{K}$. At this low temperature, changes in the properties of some of the metals have occurred, but the present work does not show any marked discontinuity in general properties corresponding to the sudden fall in electrical resistivity which exists in some metals near to the boiling point of liquid helium. The possibility of the use of liquid helium has for the moment been postponed on account of the large quantities that would be needed to effect cooling. If its use is later found to be practicable, tests would be made as low as $4.2^{\circ} \mathrm{K}$. On small specimens a study was made at this temperature in 1921 in collaboration with the late Prof. Kamerlingh Onnes and H. R. Woltjer. In those experiments they showed the absence of magnetic transformations in the iron-manganese alloys, whereas the iron-nickel alloys exhibited the presence of polymorphic transformations.

Prof. de Haas has designed the testing apparatus for this work, immersing the specimens in liquified hydrogen contained in a Dewar flask. The testing stress has been applied by an oil cylinder through a tension rod sliding inside a concentrically mounted tube. Into the ends of these two members the specimen holders have been fitted.

The specimens selected for examination not only included the materials which had previously been tested in liquid air, but also many recently developed alloys which exhibit a combination of high strength and ductility.

At liquid air temperatures, many ferrous

* "On the effect of the Temperature of Liquid Hydrogen $\left(-252 \cdot 8^{\circ} \mathrm{C}\right.$.) on the Tensile Properties of Forty-One Specimens of Metals comprising $(a)$ Pure Iron $(b)$ Four Carbon Steels $(c)$ Thirty Alloy Steels (d) Copper and Nickel (e) Four Non-Ferrous Alloys." By Prof. W. J. de Haas and Sir Robert Hadfield. Phil. Trans. Roy. Soc., A, 232, $297-332 ; 1933$. materials, including iron itself, show a marked increase in tenacity, and in general these same ferrous materials show a continued fall in ductility, which becomes negligibly small at the boiling point of hydrogen. At this temperature there is an apparent fall in strength. There are, however, some remarkable exceptions to this fact; for example, an alloy containing 6 per cent of manganese and 24 per cent of nickel shows an increase of ductility when cooled to $-194^{\circ} \mathrm{C}$., and on being further cooled to the boiling point of hydrogen, it still retains appreciable ductility. This present work thus continues the study of the iron-nickelmanganese-carbon alloys which were described in the seventh report to the Alloys Research Committee of the Institution of Mechanical Engineers in 1905 .

The 'stainless steels' and 'high temperature alloys' are two classes of materials which are not adversely affected by fall of temperature; for example, the well-known alloy containing 18 per cent of chromium and 8 per cent of nickel shows the remarkable strength of 119.8 tons per square inch, accompanied by an elongation of 25 per cent.

The non-ferrous alloys which the authors have selected are all ductile at the lowest temperature of test. The earlier work had shown that nickel, copper and aluminium increased in strength without a corresponding fall in ductility. In the present tests, the copper specimens break at $29 \cdot 7$ tons per square inch accompanied by a ductility of 60 per cent in extension, but a bronze, containing 10 per cent of tin, shows a slight reduction in properties. Good extension occurs during test of specimens of an '80/20' nickel-chromium alloy and of the aluminium alloy known as 'duralumin'. The safety of the aluminium alloy from embrittlement will be a guidance to designers of aircraft.

A consideration of the non-ferrous alloys selected for test shows that these possess a lattice structure of the face-centred cubic type which appears to allow the retention of ductility at low temperatures, but in ferrous alloys this arrangement of the atoms is not always accompanied by ductility; for example, the toughened manganese steel and the low carbon alloy of this metal with iron, are not ductile, although their structures conform at normal temperatures to the face-centred form of the cubic system. The embrittlement of austenitic manganese steel appears to be entirely unaccompanied by metallographic change of a permanent character, for the material reverts to a ductile state at normal temperatures. On the other hand, austenitic nickel steels show a change which is irreversible.

The iron alloys of the ferritic type have a bodycentred lattice and are not ductile at low temperatures. These materials contrast very strikingly with the austenitic 'stainless' and 'heat-resisting' steels, which possess a face-centred cubic structure and are not embrittled. 